\title{
Optimization of Shaft Sleeve Slippage in High-Voltage Circuit Breaker Operation Mechanism
}

\author{
Zhao Wenqiang, Zhang Haibo, Wu Shijing* and Meng Fangang
}

School of Power and Mechanical Engineering, Wuhan Univrsity, Wuhan 430072, China

\begin{abstract}
High-voltage circuit breakers are mechanical switching devices which connect and break current circuits (operating currents and fault currents) and carry the nominal current in closed position. As a result of multi-running, the shaft sleeve in operation mechanism could slip and even strip from the shaft at the hinge joint, which decreases the system reliability. In this work, investigations on the cause of sleeve slippage are proceeded, and the dimension parameters of shafting components where sleeve slippage occurs are optimized by incorporating a quasi-static mechanical model with Taguchi method. By developing and analyzing the mechanical model for the shaft sleeve slippage, it indicates that the sleeve slippage displacement has a same variation tendency with the shaft deflection. Theoretical equations are derived by using force analysis and superposition method to descript the analytic function of the shaft deflection. As the variables within the analytic function of the shaft deflection, the diameter and length of the shaft and the corresponding shaft sleeve length are selected as the control parameters in the optimization model. Moreover, several experiments are conducted by using the $L_{18}$ (mixed orthogonal array) design method. Considering that the local mechanical characteristics such as sleeve strain are difficult to monitor via experimental method, an FEM simulation model is established to give the sleeve slippage displacement. Different levels of control parameters are introduced into the mechanical model and FEM simulation according to Taguchi method. The results from signal-to-noise $(S / N)$ and ANOVA analysis (analysis of variance) reveal that shaft diameter is the most significant factor determining sleeve slippage in high-voltage circuit breaker operation mechanism, and that a larger diameter of shaft, a shorter shaft length and a longer sleeve length can reduce the sleeve slippage effectively. Meanwhile, the theoretical model is verified and enhanced by the FEM model.
\end{abstract}

Keywords: High-voltage circuit breakers, sleeve slippage optimization, FEM model, Taguchi method.

\section{INTRODUCTION}

High-voltage circuit breaker prevents system from severe damage due to overload, and so far, has been among the most important equipment for ensuring the effective and safe operation for the electric power system [1]. However, with a higher requirement in power load and mechanical response speed in industrial application, the reliability of the highvoltage circuit breaker operation mechanism is hard to be ensured due to its high working pressure and complex working condition. Besides that, multi-components exiting in operation mechanism also decrease system reliability. To ensure system reliability, components such as moving contact, rod and shaft sleeve, should be analyzed and optimized based on theory and experiment research [2].

Nowadays, lots of accidents appear in circuit breaker operation mechanism as a result of shaft sleeve slippage and falling. Song et al. [3] made a statistics of high-voltage circuit breaker failures in recent years, and mentioned that shaft fracture and sleeve falling in the connection of insulated rod and metal joint contributed most to the failure, due to parts looseness and fracture in circuit breaker. Feng et al. [4] investigated the movement characteristics of circuit breaker closing and opening. His results indicated that the shaft sleeve slippage caused the condition due to which the

Address corresponding to this author at the Wuhan University, Wuhan 430072, China; Tel: 13971663992; E-mail: wsj@whu.edu.cn operation mechanism suspended and did not resume in time, which decreased the sensitivity of operation responses. The data of twenty thousand sets of High-voltage circuit breaker were inquiried for equipment failure summary and probability statistics by Conference international des Grands Reseaux Electriques(CIGRE) from the year 1971 to 1991 [5] and the analysis of major failure in high-voltage circuit breaker indicated that looseness and slippage of shaft sleeve would lead to miss operations such as failure of closing and opening. Consequently, the shaft sleeve slippage phenomena should not be neglected to enhance system security.
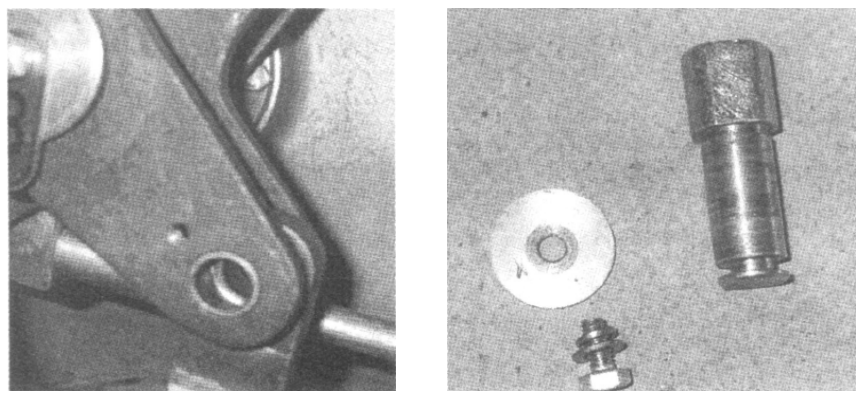

Fig. (1). A picture of moving arm and slippage shaft pin and lock plate at hinged position.

Recently, several researches have been proceeding to analyze and optimize the sleeve slippage for the circuit breaker. Ning et al. [6] optimized the machining process for higher alignment of shaft and sleeve parts by using a new 
process program to reduce repeating clamping error. Zhang et al. [7] incorporated fourth strength theory with the fatigue stress curve to investigate the influence of transition fillet on stress concentration of shaft sleeve parts. It's recommended that a big rounded corner of the shaft sleeve and improving of the parts surface quality could extend the operating life of circuit breaker mechanism effectively. Sun et al. [8] investigated the explosion reason of $110 \mathrm{kV}$ SF6 circuit breakers and found that the slippage shaft pin of moving arm was in the charge of the accident as described in Fig. (1). The cited literatures above confirm that limited investigations have been carried out on the cause of shaft sleeve slippage phenomenon. Hence in this work, an attempt is made to analyze the cause of shaft sleeve slippage and to optimize the dimension parameters of shafting components for reducing the sleeve slippage displacement.

Based on this consideration, a quasi-static mechanical model on the basis of Newton's law and a finite-element model $(F E M)$ are successfully introduced into the simulation of operation mechanism. The mechanical model takes charge to finds out the significant factors affecting sleeve slippage. The FEM model describes the evolution of strains and stresses within every step and simulates the shaft sleeve slippage from closing to opening, and calculates the displacement of shaft sleeve slippage. The FEM model for sleeve slippage is incorporated with Taguchi method [9-11] to investigate the most significant factor determining the sleeve slippage.

\section{MECHANICAL MODEL}

In this work, in order to find the key factors determining the sleeve slippage, a quasi-static mechanical model that is developed for the shaft sleeve slippage, is based on the following major assumptions at present, some of which may be relaxed as the work proceeds:

1. During the continuous movement of the mechanism, although the system has the acceleration at a certain time, the shaft parts (shafts, sleeves and so on) are assumed at quasi-static state.

2. Before bending deformation of the shaft appears, shaft sleeve and shaft contact with each other perfectly, that is to say that there is no clearance between both surfaces.

3. This mechanical model is a linear system, to which the principle of linear superposition is adapted.

4. The axial displacements of shaft and connecting rod are omitted due to a relatively large inertia force compared to the shaft sleeve.

In this mechanical model, several equilibrium equations are built-up at the hinge joint between insulation rod and moving contact, based on quasi-static analysis. From the top view and side view in Fig. (2), the shaft elastic deformation at hinged position shows that the direction of shaft bending deformation is opposite to motion direction according to the comparison between the condition before and after shaft deformation in the top view, due to the fact that a large separating brake acceleration is applied on the moving contact when circuit breaker institutions begin to overload protection. Besides that, in the view that the direction of motion and shaft sleeve slippage is orthogonal [12], no force from motion direction contributes to shaft sleeve slippage. Therefore, the shaft deformation along the direction of motion, which has no influence on shaft sleeve slippage, is neglected during the following work. From the side view in Fig. (2), the shaft bending deformation has a tendency towards gravity direction occurred, as a result of the gravity and the component contact force in the gravity direction between insulation rod and shaft.

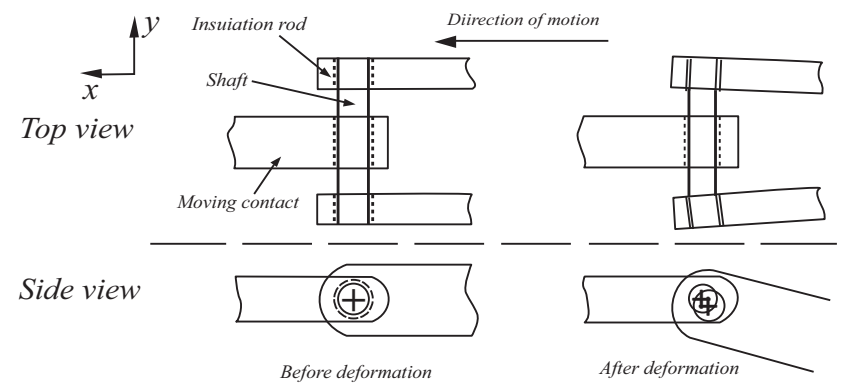

Fig. (2). Diagram of deformation at hinged position.

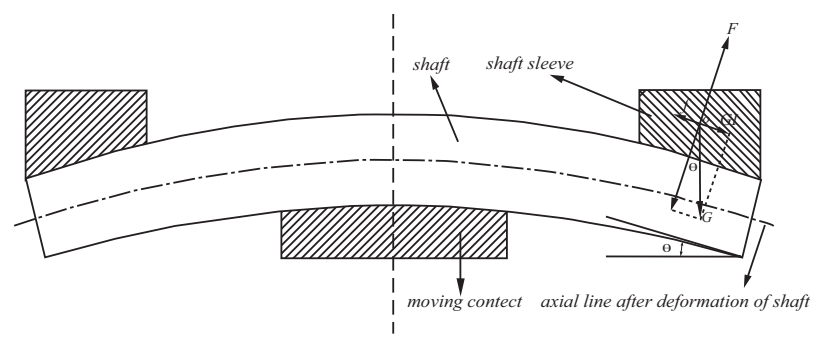

Fig. (3). An axisymmetric diagram for the force analysis of the right side of sleeve.

According to force analysis mentioned above, From the Fig. (3) that shows an axisymmetric diagram for the force analysis of the shaft sleeve, it's seen that sleeve slippage is generated mainly by the component force of the shaft sleeve gravity along the axial line after deformation $\left(G_{l}\right)$. In order to find out the key factors determining sleeve slippage, a force analysis diagram for shaft sleeve is drawn in Fig. (3). $\boldsymbol{F}$ is the contact force orthogonal with $G_{l}$ and produces the friction force $(f)$ with a friction coefficient $\eta . m a$ is the inertial force of shaft sleeve. The simultaneous equations which are obtained by quasi-static mechanical model are based on newton's second law and are given below.

$\mathrm{G}_{1}=\mathrm{G} \sin \theta$

$f=\eta F$

$G \sin \theta-f=m a$

According to Equations (3), it is revealed that under the condition of $G \sin \theta-f>0$, undoubtedly, the shaft sleeve will slip along the axial line after shaft deformation, and the establishment for condition of inequation above largely depends on the $\theta$ parameter value, which is in direct proportion to shaft deflection $w$. Hence, it's indicated that shaft deflection affects the sleeve slippage and a large shaft deflection accelerates the sleeve slippage. Therefore in this work, except for the optimization of sleeve slippage, 
minimizing the shaft deflection $w$ makes sense significantly to reduce shaft sleeve slippage.

To calculate the shaft deflection, Fig. (4) shows force analysis of shaft in static equilibrium. A simply supported beam model [8] for the shaft is established to extract the function relation between the shaft deflection $w$ and relevant independent variables. In Fig. (4), $q_{3}$ is continuously distributed load from shaft inertial force that contributes to bending deformation.

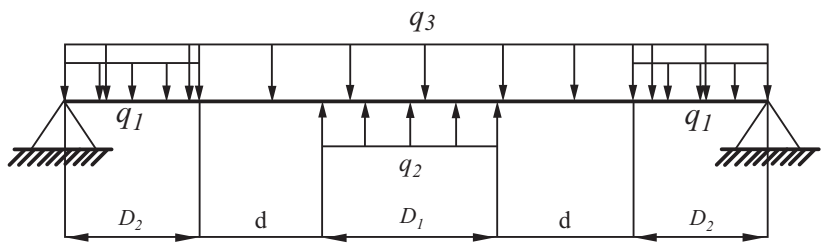

Fig. (4). Diagram of force analysis for shaft in static equilibrium.

Continuously distributed load of contact force $q_{1}$ from insulation rod is applied on both ends of shaft. $q_{2}$ is the continuously distributed load of contact force from moving contact as shown in Fig. (2). $D_{1}, D_{2}$ and $d$ represent the dimension of shaft section respectively and $D_{2}$ is also the shaft sleeve length.

The continuously distributed load $\left(q_{1} q_{2} q_{3}\right)$ calculation is given in the following equations quoted from mechanics of materials [13]:

$\mathrm{q}_{1}=\mathrm{F}_{1} / \mathrm{D}_{1}$

$\mathrm{q}_{2}=\mathrm{F}_{2} / \mathrm{D}_{2}$

$\mathrm{q}_{3}=\mathrm{ma} / \mathrm{L}$

$L$ is the shaft length. To obtain shaft deflection $w$ under the force situation shown in Fig. (4), the deflection of shaft due to respective continuously distributed loads $\left(q_{1} q_{2} q_{3}\right)$ are given by using Hooke's law [14] below. Clockwise is the plus direction:

$w_{1}=\frac{q_{1} D_{2}^{2}}{48 E I}\left(3 L^{2}-2 \mathrm{D}_{2}^{2}\right)$

$w_{2}=\frac{q_{2} D_{1} L^{3}}{384 E I}\left(8-\frac{4 D_{1}^{2}}{L^{2}}+\frac{D_{1}^{3}}{L^{3}}\right)$

$w_{3}=\frac{5 q_{3} D_{2}^{4}}{384 E I}$

$I=\pi D^{4} / 64$

Here, $w_{1} w_{2} w_{3}$ represent the shaft deflection under the continuously distributed load (q1 q2 q3) respectively. $D$ is the shaft diameter and $E$ is the elasticity modulus. According to linear superposition principle, one of the optimization objectives $w$ (shaft deflection) is given by the summation of three single deflections:

$$
\begin{aligned}
& w=-w_{1}+w_{2}-w_{3}= \\
& \frac{-8 q_{1} D_{2}^{2}\left(3 L^{2}-2 \mathrm{D}_{2}^{2}\right)+q_{2} D_{1} L^{3}\left(8-\frac{4 D_{1}^{2}}{L^{2}}+\frac{D_{1}^{3}}{L^{3}}\right)-5 q_{3} D_{2}^{4}}{384 E I}
\end{aligned}
$$

Table 1. Control parameters and their levels.

\begin{tabular}{|c|c|c|c|c|}
\hline Parameters & Symbol & Level 1 & Level 2 & Level 3 \\
\hline \hline Shaft diameter(mm) & $A$ & 18 & 24 & -- \\
\hline Shaft length(mm) & $B$ & 72 & 76 & 80 \\
\hline Shaft sleeve length(mm) & $C$ & 13 & 15 & 17 \\
\hline
\end{tabular}

According to the Equations (11), it's seen that external incentives generated by loading and the internal dimension of shaft parts together determine the shaft deflection $w$. Furthermore, the independent variables in Equations (11) such as $D$ (shaft diameter), $L$ (shaft length) and $D_{2}$ (shaft sleeve length), commonly have certain effects on shaft sleeve slippage according to the conclusion that a big shaft deflection accelerates the sleeve slippage. In the view that nonlinear contact element involved in external incentives is hard to be controlled in experiment and applications [15], this work selects the dimensions of shaft components as the optimization control parameters, where the length and diameter of the shaft as well as the shaft sleeve length are selected as control parameters from Equations (11) as shown in Table 1. The selection of the level values for each control parameter depends on the experimental data from PingGao Technology. It is obvious that sleeve slippage will decrease with the increase of shaft diameter as a result that the stiffness of the shaft will increase and the shaft deflection will decrease, therefore the control parameter $A$ (shaft diameter) has two different level values, and three different levels values are assigned for shaft length and shaft sleeve length respectively, for a better exploring of the effects tendency of control parameters $B$ (shaft length) and $C$ (shaft sleeve length) on sleeve slippage.

\section{EXPERIMENTAL DESIGN}

\subsection{Mechanical Properties for ABAQUS Simulation}

The use of finite-element method (FEM) is based on the following considerations:

a) Even if the quasi-static mechanical model built for shaft sleeve slippage is totally appropriate, FEM can serve as the verification for the mechanical model.

b) FEM is convenient to calculate the sleeve slippage displacement in by explicit dynamics, but the quasistatic mechanical model lacks the capacity in this area. FEM simulation possesses the superiority to solve the nonlinear contact problem [16-18].

In the view of the complicated geometry structure of high-voltage circuit breaker operation mechanism and unpredictable contact problem, ABAQUS/ Explicit is an optimal option and selected as the solver for FEM simulation.

First of all, the input parameters describing the mechanism geometry structure can be totally submitted into mechanical model. Then, the dynamic model built in ABAQUS (Fig. 5a) via the cable geometry is defined by 
Table 2. Geometrical properties and analysis settings of explicit dynamic analysis in ABAQUS.

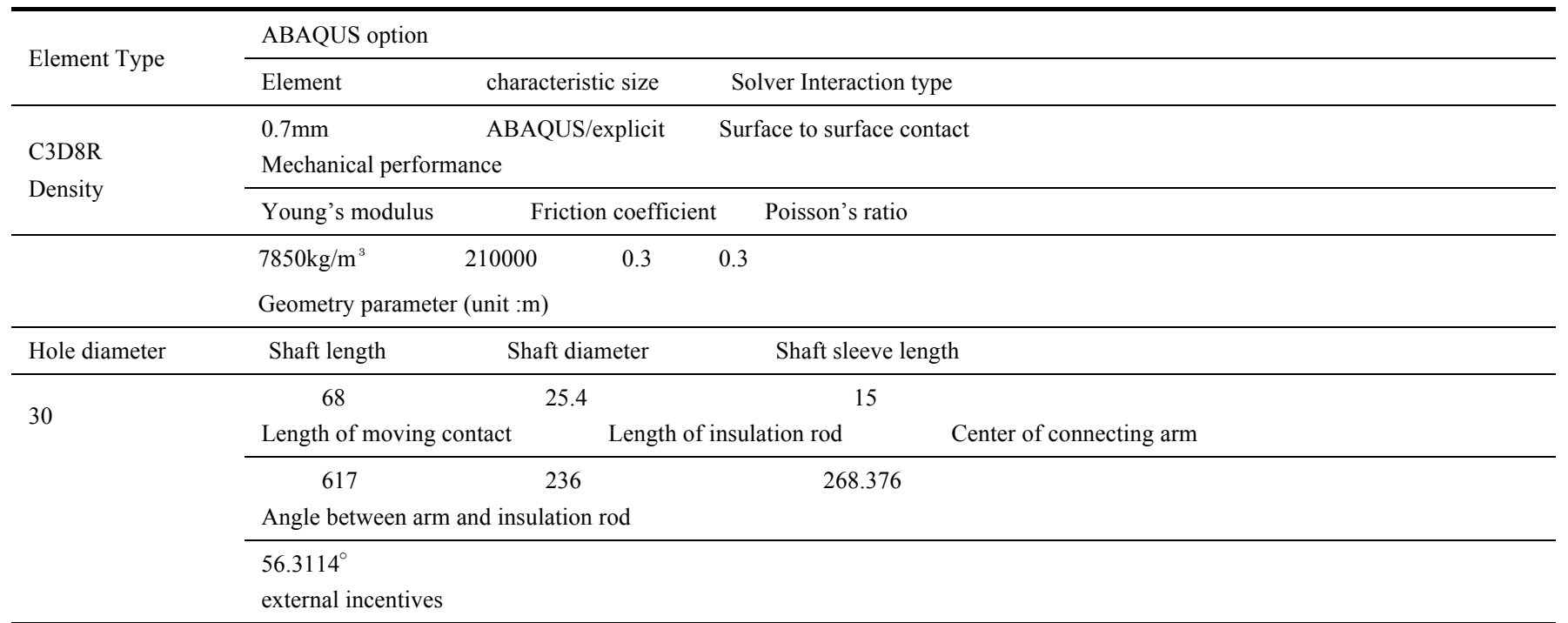

\begin{tabular}{c|c}
\hline Pressure on moving contact & Arm rotating angle(rad) in simulation time(s) \\
\hline $15 \mathrm{MPa}$ & $1 \mathrm{rad}$ in 0.04 second \\
\hline
\end{tabular}

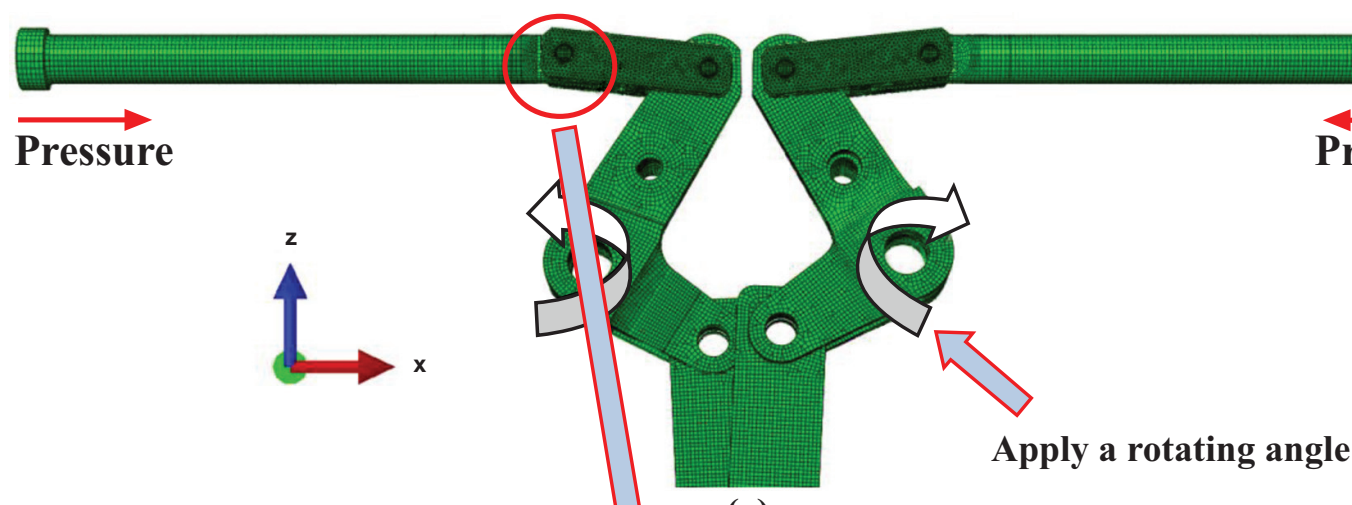

(a)

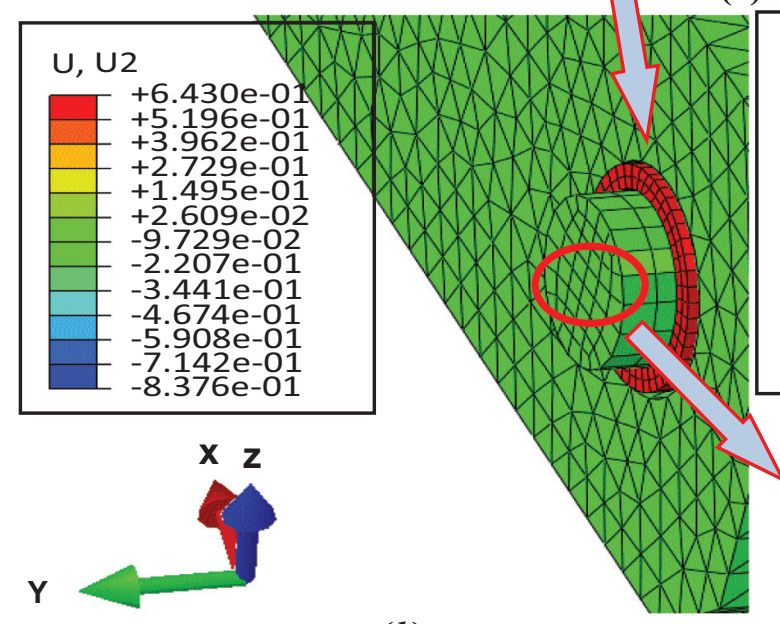

(b)

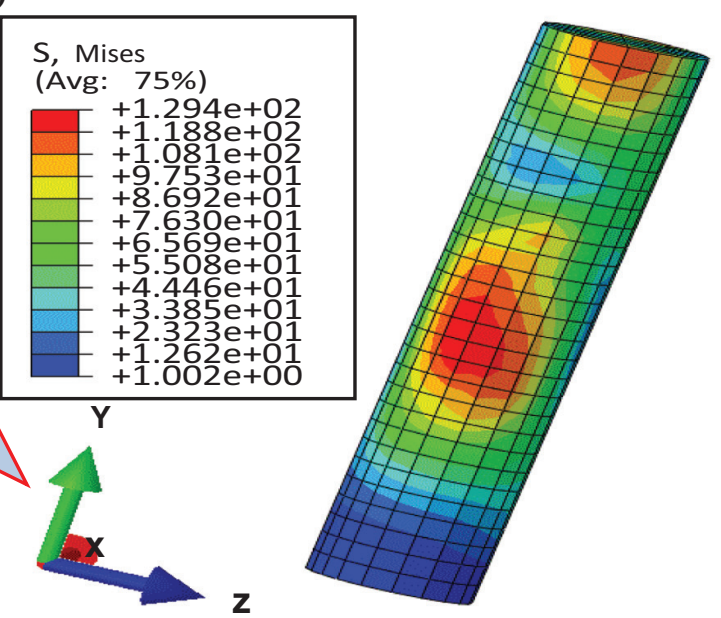

(c)

Fig. (5). FEM simulation under load applied in Table 2, (a) mechanism geometry model and load, (b) sleeve slippage simulation cloud, (c) stress of the shaft.

equations describing the high-voltage circuit breaker mechanism. Geometrical parameters of circuit breaker are selected according to experimental samples from PingGao Technology. It is observed from Fig. (5b) that a slippage displacement $0.64 \mathrm{~mm}$ appears. From Fig. (5c), it indicates that a large stress appeared in the center of shaft and thus produces the shaft deflection, which is calculated in the FEM model and Equation (11). 


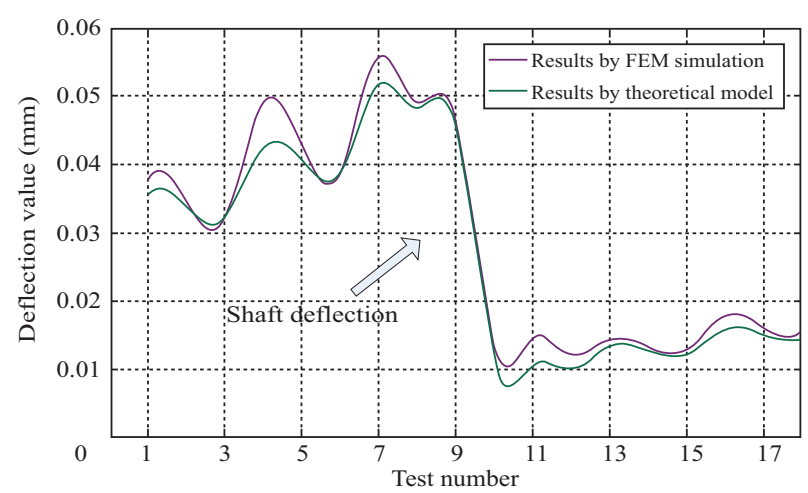

Fig. (6). Comparison between theoretical and experimenttal results.

In this work, ABAQUS meshes the strand bundle with $3 \mathrm{D}$ solid elements [16]. The input data for ABAQUS is presented in Table 2, which is also available for the theoretical model. Table 1 shows the control parameters (control factors) and their levels. According to the $L_{18}$ orthogonal array for experiment parameter design in Table $\mathbf{3}$, 18 kinds of different configurations for the three control parameters $(A, B, C)$ are taken into the explicit-dynamic analysis module in ABAQUS to calculate the load distribution on the shaft, the shaft deflection and the sleeve slippage displacement. Then according to the test number, the continuously distributed loads $q 1 q 2$ q3 as well as the corresponding level values of control parameter are taken into Equations (11) to calculate the shaft deflection in mechanical model, and the theoretical values of shaft deflection are shown in Table 3. Fig. (6) shows the results comparison of the shaft deflection from mechanical model and FEM calculation by ABAQUS/Explicit. From the Fig. (6), the section between test number 1 and 9 and the section between test number 10 and 18 have a similarity in both the changing tendency and amplitude values of shaft deflection. Besides that, a significant jump of shaft deflection amplitude appears between the test nine and ten as a result of shaft diameter decreasing from the test nine to ten. Therefore it's inferred that shaft diameter is a significant control parameter determining the shaft deflection and even sleeve slippage in all three control parameters. In order to find out the most significant control parameter determining sleeve slippage and figure out the optimum configuration of control parameters and their levels, Taguchi method is incorporated with the signal-to-noise analysis and $A N O V A$ method [9-11].

\subsection{Taguchi Method}

The Taguchi method has been widely used in engineering analysis for industrial production optimization processes [19, 20]. By using orthogonal arrays and control parameter levels, this method reduces the number of tests significantly. The deviation between the test values and the desired values is calculated by a signal-noise $(S / N)$ ratio $(\eta)[20,21]$. The percentage contributions to slippage from the length $(L)$ and diameter $(D)$ of the shaft sleeve as well as the shaft length $\left(D_{2}\right)$ are reflected in the analysis of variance $(A N O V A)$. In this work, to minimizing the shaft deflection $w$ in Equations (11) and the sleeve slippage displacement are both optimization objectives. Therefore, in three kinds of measurement model for optimization [22], "the lower-thebetter" model is selected for measuring the quality characteristic in this work as shown in Equations (12).

Lower -the-better (minimize):

$\eta=\frac{S}{N_{s}}=-10 \log \left[\frac{1}{n} \sum_{i=1}^{n} y_{i}^{2}\right]$

where $y_{i}$ is the observed data at the $i$ th test and $\mathrm{n}$ is the repeated test number of observations [23]. Table 1 shows control parameter levels, which are distributed in the $L_{18}$ mixed orthogonal array as showed in Table $\mathbf{3}$, where the shaft deflections calculated by Equations (11) are listed under corresponding factor configurations. The most suitable orthogonal array $L_{18}\left(2^{1} \times 3^{2}\right)$ is selected to determine the optimal parameters configuration and evaluate the influence of control parameters on optimization objectives [24].

\section{ANALYSIS AND EVALUATION OF RESULTS}

\subsection{Analysis of the Signal-to-Noise (S/N) Ratio}

The lowest values of shaft deflection and sleeve slippage are very important for the quality improvement of the highvoltage circuit breaker and lowering fault. Table 4 shows the values of the $S / N$ ratios for observations of the shaft deflection and sleeve slippage displacement in FEM simulation. $S D$ and $S S$ represent the shaft deflection and sleeve slippage displacement respectively. At the end of the table, the mean values of shaft deflection and sleeve slippage displacement are calculated to be $0.0287 \mathrm{~mm}$ and $0.627 \mathrm{~mm}$ respectively. Similarly, mean values of $S / N$ ratio for shaft deflection and sleeve slippage displacement are $32.166 \mathrm{~dB}$ and $4.398 \mathrm{~dB}$ respectively

Analysis of the influence of each control factor $(A, B, C)$ on the shaft deflection and sleeve slippage are proceeded with a " $S / N$ response table" in Table 5. The highest $S / N$ ratio in the levels is the best level for each control factor for minimizing the sleeve slippage, and the levels and $S / N$ ratios for the factors giving the best $S D$ (shaft deflection) value are specified as factor $A$ (Level 2, $S / N=36.853$ ), factor $B$ (Level $1, S / N=33.359$ ) and factor $C$ (Level $3, S / N=32.845)$. In other words, the minimum shaft deflection value is obtained with a shaft diameter $(A 2) 24 \mathrm{~mm}$, with shaft length $(B 1)$ $72 \mathrm{~mm}$ as well as sleeve length $(C 3) 17 \mathrm{~mm}$ in all $18 \mathrm{kinds}$ of parameter configurations. Similarly, the levels and $S / N$ ratios for the factors giving the minimum $S S$ (sleeve slippage) are specified as factor $A$ (Level $2, S / N=6.092$ ), factor $B$ (Level $1, S / N=6.092$ ) and factor $C$ (Level $3, S / N=5.560)$. From the comparison of the $S / N$ graph Fig. (7a, b), it's concluded that the change of $S S$ and $S D$ has the same tendency with different factor level, and the shaft diameter is the most effective parameter to reduce shaft deflection and sleeve slippage in three control parameters $(A, B, C)$.

\subsection{Evaluation of Experimental Results}

In order to figure out the influences of each control parameter on the optimization results, a group of FEM simulation results that are obtained under representative control parameters configurations are listed in Fig. (8). 
Table 3. Full factorial design with $L_{18}$ orthogonal array of Taguchi.

\begin{tabular}{|c|c|c|c|c|}
\hline Experiment No. & Factor A & Factor B & Factor C & Theoretical Deflection \\
\hline 1 & 1 & 1 & 1 & 0.0355 \\
\hline 2 & 1 & 1 & 2 & 0.0339 \\
\hline 3 & 1 & 1 & 3 & 0.0320 \\
\hline 4 & 1 & 2 & 1 & 0.0424 \\
\hline 5 & 1 & 2 & 2 & 0.0406 \\
\hline 6 & 1 & 2 & 3 & 0.0386 \\
\hline 7 & 1 & 3 & 1 & 0.0517 \\
\hline 8 & 1 & 3 & 2 & 0.0482 \\
\hline 9 & 1 & 3 & 3 & 0.0459 \\
\hline 10 & 2 & 1 & 1 & 0.0112 \\
\hline 11 & 2 & 1 & 2 & 0.0107 \\
\hline 12 & 2 & 1 & 3 & 0.0101 \\
\hline 13 & 2 & 2 & 1 & 0.0134 \\
\hline 14 & 2 & 2 & 2 & 0.0128 \\
\hline 15 & 2 & 2 & 3 & 0.0122 \\
\hline 16 & 2 & 3 & 1 & 0.0159 \\
\hline 17 & 2 & 3 & 2 & 0.0152 \\
\hline 18 & 2 & 3 & 3 & 0.0145 \\
\hline
\end{tabular}

Table 4. Results of experiments and $S / N$ ratios values.

\begin{tabular}{|c|c|c|c|c|c|c|c|}
\hline \multirow{2}{*}{$\begin{array}{c}\text { Experiment } \\
\text { No. }\end{array}$} & \multicolumn{3}{|c|}{ Control Factors } & \multirow{2}{*}{$\begin{array}{c}\text { Shaft } \\
\text { Deflection } \\
S D,(\mathrm{~mm})\end{array}$} & \multirow{2}{*}{$\begin{array}{c}S / N \text { Ratio } \\
\text { for } S D,(\mathrm{db})\end{array}$} & \multirow{2}{*}{$\begin{array}{c}\text { Slippage } \\
\text { Displacement } \\
S S,(\mathrm{~mm})\end{array}$} & \multirow{2}{*}{$\begin{array}{c}S / N \text { Ratio } \\
\text { for } S S,(\mathrm{db})\end{array}$} \\
\hline & $A$ ShaftDiameter & $B$ Shaft Length & $C$ Shaft Sleeve Length & & & & \\
\hline 1 & 18 & 72 & 13 & 0.0378 & 28.450 & 0.7625 & 2.337 \\
\hline 2 & 18 & 72 & 15 & 0.0346 & 29.218 & 0.7100 & 2.975 \\
\hline 3 & 18 & 72 & 17 & 0.0320 & 29.897 & 0.6487 & 3.759 \\
\hline 4 & 18 & 76 & 13 & 0.049 & 26.196 & 0.7642 & 2.336 \\
\hline 5 & 18 & 76 & 15 & 0.0426 & 27.412 & 0.7236 & 2.810 \\
\hline 6 & 18 & 76 & 17 & 0.0386 & 28.268 & 0.5968 & 4.483 \\
\hline 7 & 18 & 80 & 13 & 0.0557 & 25.083 & 0.8742 & 1.168 \\
\hline 8 & 18 & 80 & 15 & 0.0489 & 26.214 & 0.8009 & 1.928 \\
\hline 9 & 18 & 80 & 17 & 0.0469 & 26.577 & 0.7469 & 2.535 \\
\hline 10 & 24 & 72 & 13 & 0.0132 & 37.589 & 0.4583 & 6.777 \\
\hline 11 & 24 & 72 & 15 & 0.0147 & 36.654 & 0.3672 & 8.702 \\
\hline 12 & 24 & 72 & 17 & 0.0121 & 38.344 & 0.2883 & 10.803 \\
\hline 13 & 24 & 76 & 13 & 0.0144 & 36.833 & 0.5665 & 4.936 \\
\hline 14 & 24 & 76 & 15 & 0.0133 & 37.523 & 0.4479 & 6.976 \\
\hline 15 & 24 & 76 & 17 & 0.0129 & 37.788 & 0.4205 & 7.525 \\
\hline 16 & 24 & 80 & 13 & 0.0179 & 34.944 & 0.7983 & 1.957 \\
\hline 17 & 24 & 80 & 15 & 0.0162 & 35.810 & 0.7160 & 2.902 \\
\hline 18 & 24 & 80 & 17 & 0.0155 & 36.193 & 0.6126 & 4.256 \\
\hline
\end{tabular}

$\mathrm{T}_{\mathrm{SD}}$ (shaft deflection total mean value) $=0.0287 \mathrm{~mm}$.

$\mathrm{T}_{\mathrm{SD}-S / N}($ shaft deflection $S / N$ ratio total mean value $)=32.166 \mathrm{~dB}$.

$\mathrm{T}_{\mathrm{SS}}$ (sleeve slippage displacement mean value) $=0.627 \mathrm{~mm}$

$\mathrm{T}_{\mathrm{SS}-S / N}($ sleeve slippage displacement $S / N$ ratio total mean value $)=4.398 \mathrm{~dB}$. 
Table 5. Average $S / N$ response table for shaft deflection and sleeve slippage.

\begin{tabular}{|c|c|c|c|c|c|c|}
\hline \multirow{2}{*}{ Levels } & \multicolumn{6}{|c|}{ Control Parameter } \\
\cline { 2 - 8 } & $\boldsymbol{A}$ & $\boldsymbol{B}$ & $\boldsymbol{C}$ & $\boldsymbol{A}$ & $\boldsymbol{B}$ & $\boldsymbol{C}$ \\
\cline { 2 - 8 } & 27.479 & $\mathbf{3 3 . 3 5 9}$ & 31.516 & 2.703 & $\mathbf{5 . 8 9 2}$ & 3.252 \\
\hline \hline Level 1 & $\mathbf{3 6 . 8 5 3}$ & 32.337 & 32.139 & $\mathbf{6 . 0 9 2}$ & 4.844 & 4.382 \\
\hline Level 2 & & 30.804 & $\mathbf{3 2 . 8 4 5}$ & & 2.458 & $\mathbf{5 . 5 6 0}$ \\
\hline Level 3 & & & & & \\
\hline
\end{tabular}

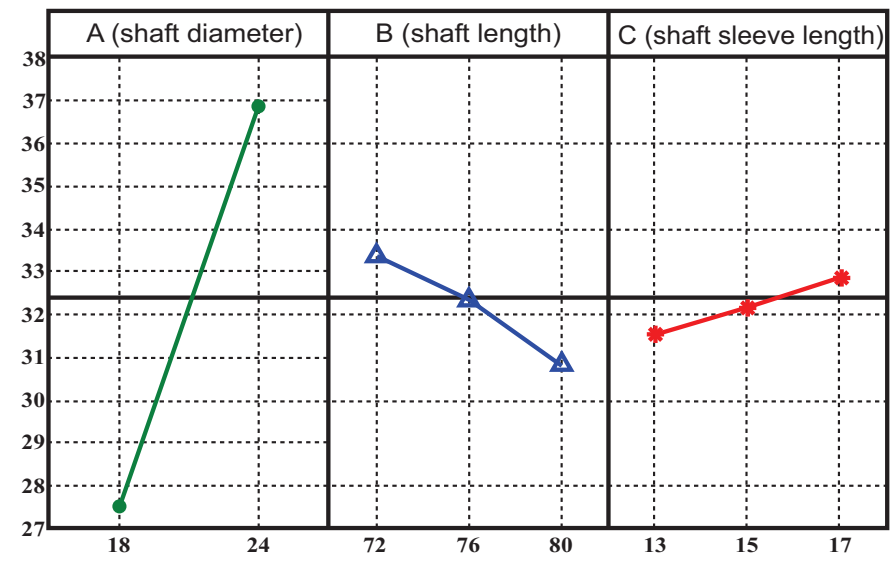

(a)

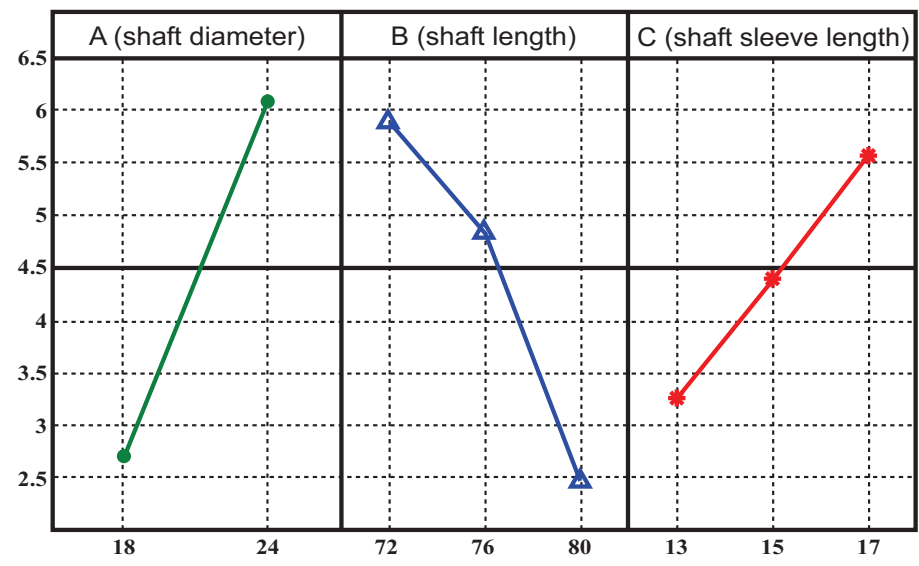

(b)

Fig. (7). The $S / N$ graph of main effective factors: (a) $S / N$ graph for shaft deflection. (b) $S / N$ graph for sleeve slippage displacement.

According to results comparison of $A 2 B 1 C 3$ and $A 1 B 1 C 3$ and comparison of $\mathrm{A} 2 \mathrm{~B} 3 \mathrm{C} 3$ and $\mathrm{A} 1 \mathrm{~B} 3 \mathrm{C} 3$, a large shaft diameter $(A 2)$ obviously results in a smaller sleeve slippage displacement (U2). According to results comparison of $A 2 B 1 C 3$ and $A 2 B 3 C 3$ and comparison of $A 1 B 1 C 3$ and $A 1 B 3 C 3$, a short shaft length $(B 1)$ produces a smaller sleeve slippage displacement (U2). According to results comparison of $A 1 B 1 C 3$ and $A 1 B 1 C 1$ and comparison of $A 1 B 3 C 3$ and $A 1 B 3 C 1$, a long shaft sleeve length $(C 3)$ obviously generates a smaller sleeve slippage displacement (U2). The effects of control parameters on the shaft deflection and sleeve slippage are also seen in Figs. (9, 10) respectively. Depending on the difference of the sleeve length, little change appears in the shaft deflection, although a long sleeve length $\left(D_{2}\right)$ can increase the shaft support stiffness in Fig. (4).

For two different levels values of the shaft diameter, a decreasing tendency of shaft deflection and sleeve slippage displacement values appears with decreasing the shaft length. That's the reason that decreasing shaft length increases the shaft stiffness and decrease the shaft bending deformation. Therefore, increasing in the shaft length has always been an important factor to reduce shaft deflection and sleeve slippage. From the Figs. $(\mathbf{9}, \mathbf{1 0})$, it's observed that shaft diameter and shaft length are the more significant 


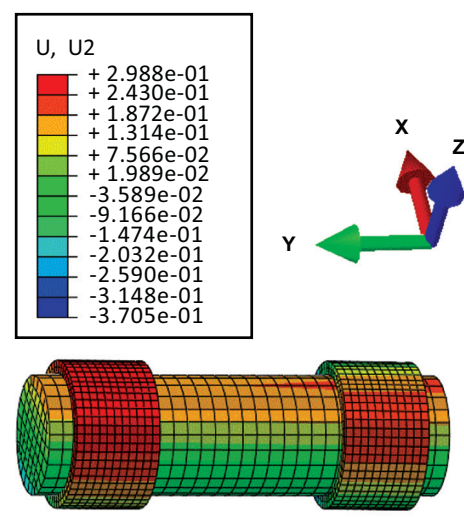

A2B1C3

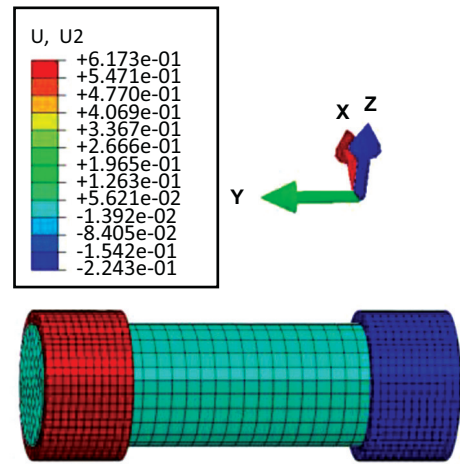

A2B3C3

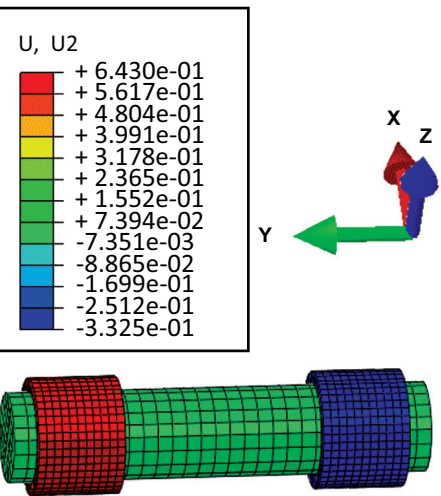

A1B1C3

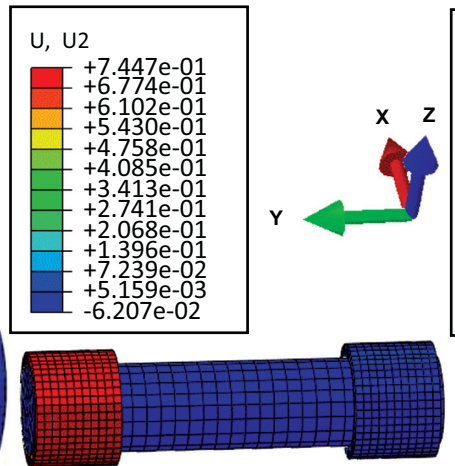

A1B3C3

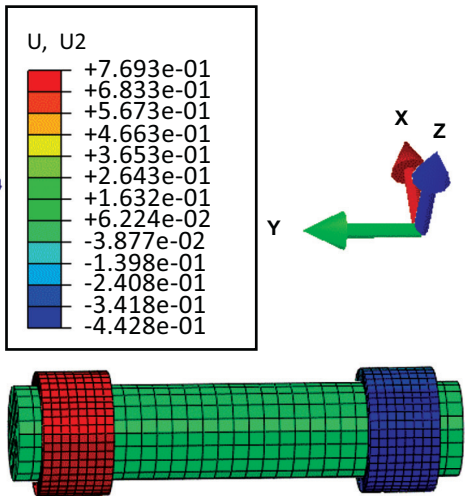

A1B1C1

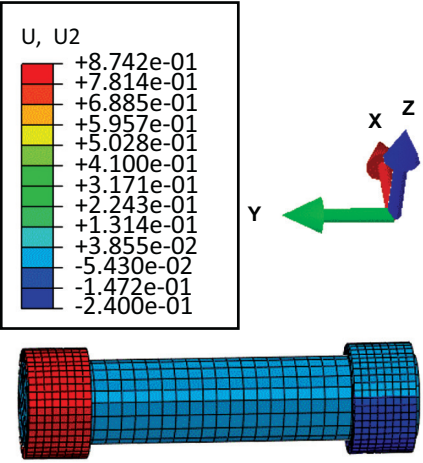

A1B3C1

Fig. (8). FEM simulation results for shaft sleeve slippage displacement (U2) under representative control parameter configurations.

parameters to reduce sleeve slippage, compared with the shaft sleeve length. As a result that the shaft deflection is a function of shaft diameter and shaft length, the change of both cause significant responses in shaft deflection value, which has the same tendency with sleeve slippage displacement.

\subsection{ANOVA Method}

ANOVA is a statistical method and is used to determine the individual interactions among all control factors in the

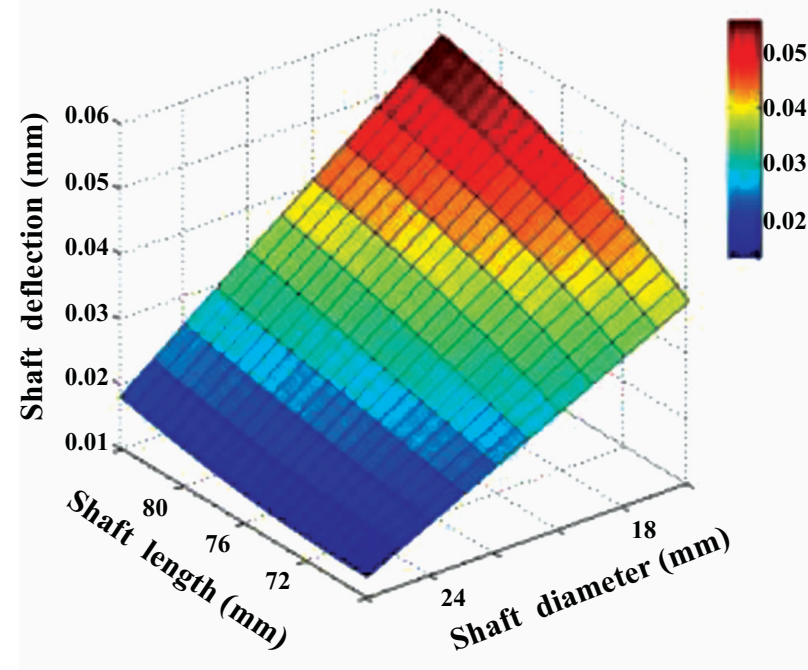

test design. In this work, ANOVA is used to assess the influences of shaft diameter, shaft length and sleeve length on shaft deflection and sleeve slippage, and is conducted for a $95 \%$ confidence level to identify the control parameters that determine the shaft deflection and sleeve slippage. Statistically, F-tests provided a decision at some confidence level that is the realized significance levels, for each source of variation as shown in Table 6. The significance of control parameters in $A N O V A$ are determined by their corresponding $\mathrm{F}$ values. The last column of the table shows the percentage value of each control parameter contribution that indicates

Fig. (9). Effect of the shaft parameters on shaft deflection.

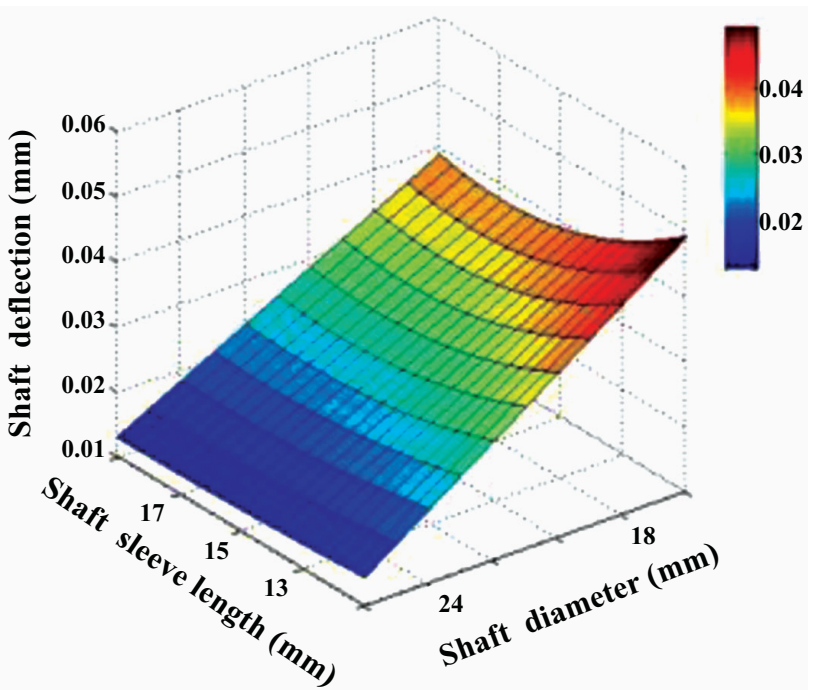



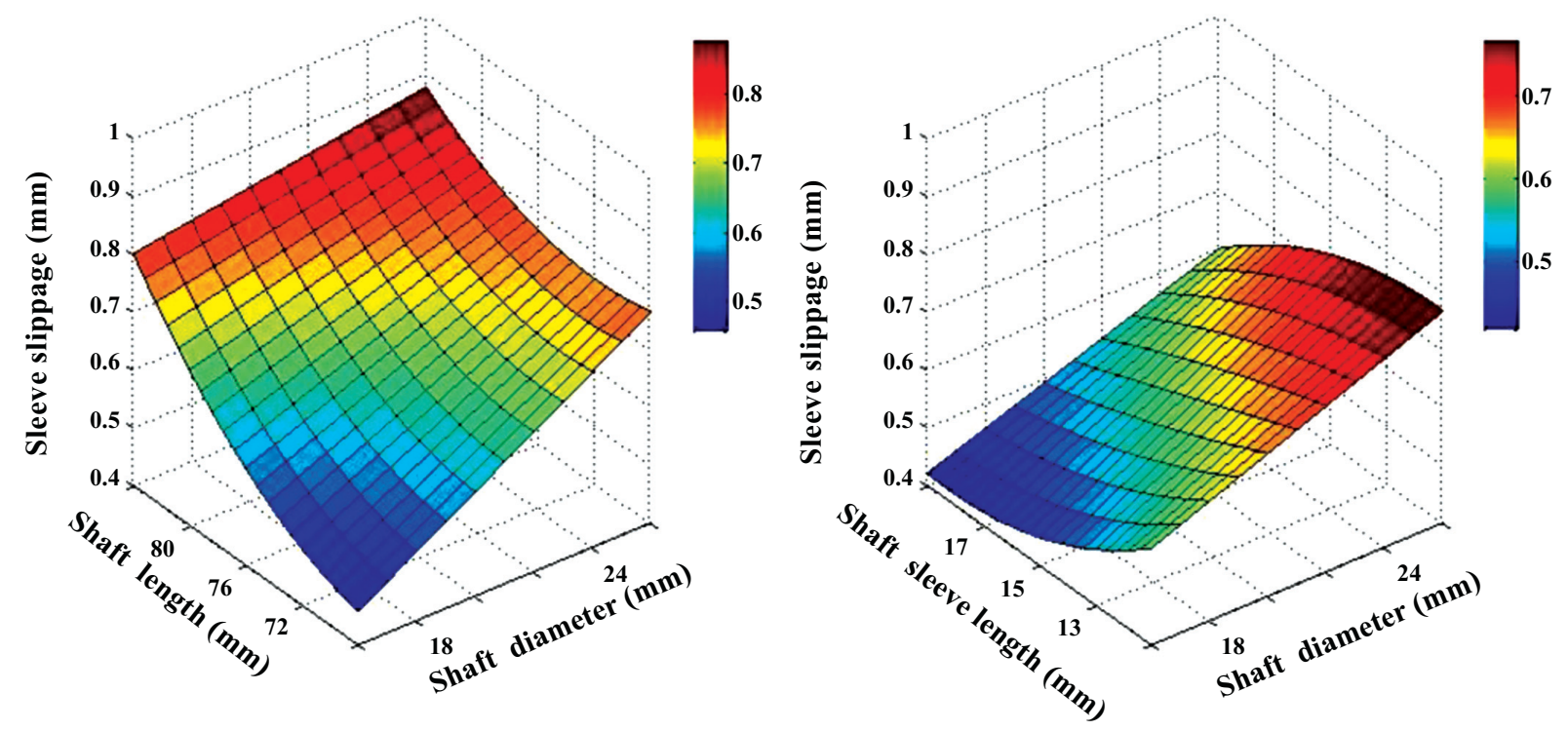

Fig. (10). Effect of the shaft parameters on shaft sleeve.

the weight of influence on the shaft deflection and sleeve slippage displacement for each control parameter. According to Table 6, the percent contributions of the $A, B$ and $C$ factors on the shaft deflection are found to be $87.65 \%, 6.40 \%$ and $1.83 \%$ respectively. Similarly, the most important factor determining sleeve slippage is the shaft diameter (factor $A$, $43.47 \%$ ), and shaft length also play an important role (factor $B, 32.72 \%$ ), compared with the shaft sleeve length (factor $C$, $14.18 \%)$.

In order to affirm that the system has realized the optimization accurately enough, the following equations are used in the specification of the confidence interval for the shaft deflection $(D S)$ and the shaft sleeve slippage (SS):

$C I=\sqrt{\frac{F_{\alpha}(1, E D) \cdot M S E}{\eta}}$

$\eta=\frac{N}{1+D O F(A+B+C)}$

where $F_{a}(1, E D)$ is the $\mathrm{F}$ ratio at a $95 \%$ confidence and $a$ is $\operatorname{Risk}(0.05) . E D$ and $M S E$ represent the degrees of freedom and the mean square of error respectively. Here, $N$ is the total test number and $\eta=18 /(1+1+2+2)=3$ (Equations(14)). $F_{0.05}(1, E D)=F_{0.05}(1,12)=4.75 \quad$ (from $\mathrm{F}$ test table), $M S E=0.01 \times 10^{-3}$ and $3.91 \times 10^{-3}$ for calculating the shaft deflection and sleeve slippage respectively. By using Equation (13) the confidence intervals of $S D$ and $S S$ are calculated as $C I_{S D}= \pm 0.004$ and $C I_{S S}= \pm 0.079$. The minimum shaft deflection and sleeve slippage obtained under the optimal control parameter configureation $(A 2 B 1 C 3)$ by using the FEM simulation are: $S D_{o p t}=0.0121(\mathrm{~mm})$ and $S S_{\text {opt }}=0.2883(\mathrm{~mm})$. The minimum shaft deflection obtained under the optimal control parameter configuration $(A 2 B 1 C 3)$

Table 6. Results of $A N O V A$ analysis for shaft deflection and shaft sleeve slippage.

\begin{tabular}{|c|c|c|c|c|c|}
\hline Variance Source & Degree of Freedom & Sum of Squares $* 10^{-3}$ & Mean Square *10 $10^{-3}$ & F Value & Contribution Rate (\%) \\
\hline \multicolumn{6}{|l|}{ Shaft deflection: } \\
\hline Shaft length & 2 & 0.26 & 0.13 & 9.32 & 6.40 \\
\hline sleeve length & 2 & 0.08 & 0.04 & 2.67 & 1.83 \\
\hline Total & 17 & 4.15 & 0.01 & & 100 \\
\hline \multicolumn{6}{|l|}{ Sleeve slippage: } \\
\hline Shaft diameter & 1 & 211.71 & 211.71 & 54.15 & 43.47 \\
\hline Shaft length & 2 & 159.36 & 79.68 & 20.38 & 32.72 \\
\hline
\end{tabular}


by using the theoretical equations is: $S D_{\text {theory }}=0.0101(\mathrm{~mm})$. With an establishment of the inequation : $\left[S D_{o p t}-C I_{S D}\right]<$ $S D_{\text {theory }}<\left[S D_{\text {opt }}+C I_{S D}\right]=[0.0121-0.004]<0.0101<$ $[0.0121+0.004]$, the minimum shaft deflection value obtained from theoretical equation stays within the confidence interval limits. Thus, the system optimization for shaft deflection and sleeve slippage is achieved using the theoretical model and Taguchi method at a significance level of 0.05 .

\section{CONCLUSION}

In this study, a quasi-static mechanical model for shaft sleeve slippage is built and incorporated with FEM simulation to calculate the shaft deflection and sleeve slippage displacement, based on Taguchi method and $L_{18}$ orthogonal array design table. According to the results evaluated by using $S / N$ ratios and $A N O V A$ method, the following conclusions are drawn:

1. According to the verification of confidence interval and the results comparison between mechanical model and FEM simulation, the results from mechanical model are in close agreement with the FEM simulation results.

2. The optimum levels of the control factors for minimizing the shaft deflection and sleeve slippage using $\boldsymbol{S} / \boldsymbol{N}$ ratios are observed both at $\mathrm{A} 2 \mathrm{~B} 1 \mathrm{C} 3$ (e.g., shaft diameter $24 \mathrm{~mm}$, shaft length $72 \mathrm{~mm}$ and sleeve length $17 \mathrm{~mm}$ ), which indicates that a larger diameter of shaft, a shorter shaft length and a longer sleeve length can reduce the sleeve slippage effectively.

3. According to the results of statistical analyses, it is found that the shaft diameter is the most effective parameter to reduce the shaft sleeve slippage with a percentage contribution of $43.47 \%$ and that the second important parameter is shaft length with a percentage contribution of $32.72 \%$. Increasing the shaft diameter appropriately can reduce sleeve slippage efficiently.

All of these results show that mechanical model for the shaft sleeve slippage and the Taguchi method both are reliable methodologies to analyze the shaft deflection and sleeve slippage in high-voltage circuit breaker operation mechanism. In the future, the results can be used for academic research as well as for industrial applications. Further studies can consider the influence of nonlinear characteristic in circuit breaker operation mechanism such as contact loading and deformation in the motion pair on shaft sleeve slippage.

\section{CONFLICT OF INTEREST}

The authors confirm that this article content has no conflict of interest.

\section{ACKNOWLEGEMENTS}

The authors would like to thank the PingGao Technology for the financial and technological support given to this study through the project "High voltage circuit breaker hydraulic operating mechanism characteristic research" Project no 208239881.

\section{REFERENCES}

[1] J. Lopez-Roldan, R. Pater, S. Poirier, D. Birtwhistlee, T. Tangd, R. Docheb, and M. Blundellc, "Development of non-intrusive monitoring for reactive switching of high voltage circuit breaker," International Journal of Electrical Power \& Energy Systems, vol. 61, pp. 219-228, 2014

[2] Kołowrocki, and Krzysztof, "Reliability of Large Systems," John Wiley \& Sons, Ltd, USA, 2008.

[3] G. Song, J. C. Cui, and D. L. Yuan, "Operating analysis of high voltage circuit breaker in 1999-2003," Electrical Equipment, vol. 2 pp. 001, 2005.

[4] H. T. Feng, "An introduction to the common fault treatment of 6 kV vacuum circuit breaker," Guangdong Technology, vol. 18, pp. 125-126, 2008 .

[5] G. Mazza, and R. Michaca, "The first international enquiry on circuit-breaker failures and defects in service," Electra, vol. 79, pp. 21-91, 1981.

[6] C. Ning, "Alignment quality improvement for rod, shaft, sets of ring part," New Technology \& New Process, vol. 12, pp. 85-87, 2012.

[7] L. Zhang, and M. Zhou, "The shaft pin reliability design of the circuit breaker operating mecha-nism," Machine Manufacturing, vol. 42, no. 12, pp. 36-38, 2005.

[8] D. L. Sun, "Analysis on $110 \mathrm{kV} \mathrm{SF}_{6}$ breaker explosion," Northeast Electric Power Technology, vol. 3, pp. 37-39, 2010.

[9] Kumar, and Vinod, "Application of taguchi and FEM to explore the surface properties of glass using USM process," American Journal of Mechanical Engineering, vol. 2, no. 1, pp. 1-7, 2014.

[10] T. I. Ogedengbe, and S. Mekid, "Application of finite element analysis and Taguchi method to robust design of a micro milling machine structure," International Journal of Design Engineering, vol. 4, no. 3, pp. 197-219, 2011.

[11] R. Ohdar, M. I. Equbal, and V. Kumar, "Die stress optimization using finite element and taguchi method," Materials Science Forum, p. 762, 2013

[12] D. K. Tam, A. L. Teten, and Q. Nguyen, "Linear and orthogonal models of acculturation and its relations to cultural variables: an examination of the Suinn-Lew Asian Self-Identity Acculturation Scale (SL-ASIA)," International Journal of Inter-cultural Relations, vol. 35, no. 1, pp. 61-68, 2011.

[13] B. A. Peter, R. J. Schmidt, and O. M. Sidebottom, "Advanced Mechanics of Materials," Wiley, New York, USA, vol. 5, 1993.

[14] Lempriere, and B. Michael, "Ultrasound and Elastic Waves: Frequently Asked Questions," Academic Press, USA, 2003.

[15] Y. X. Li, X. Wang, Y. W. Gao, Y.H. Zhou, "Modeling for mechanical response of CICC by hierarchical approach and ABAQUS simulation," Fusion Engineering and Design, vol. 88, no. 11, pp. 2907-2917, 2013.

[16] C. W. Shih, G.Y Tzou, and K.H. Chang, "Effects of forging stream line on tensile strength using FEM simulation," Advances in Mechanical Engineering, vol. 2014, Article ID 216246, 9 pages, 2014.

[17] E. Armentani, F. Caputo, and R. Citarella, "Fem sensitivity analyses on the stress levels in a human mandible with a varying atm modelling complexity" Open Mechanical Engineering Journal, vol. 4, no. 1, pp. 8-15, 2010.

[18] Yu, and Su, "3D FEM simulation of water vapor jet assisted metal cutting”, Open Mechanical Engineering Journal, vol. 8, no. 1, pp. 132-137, 2014

[19] K. Palanikumar, "Experimental investigation and optimisation in drilling of GFRP composites," Measurement, vol. 44, no. 10, pp. 2138-2148, 2011.

[20] I. Asiltürk, and H.Akkuş, "Determining the effect of cutting parameters on surface roughness in hard turning using the Taguchi method," Measurement, vol. 44, no. 9, pp.1697-1704, 2011.

[21] D. Liu, and Y. Cai, "Taguchi method for solving the economic dispatch problem with nonsmooth cost functions," IEEE Transactions on Power Systems, vol. 20, no. 4, pp. 2006-2014, 2005.

[22] A. Gupta, H. Singh, and A. Aggarwal, "Taguchi-fuzzy multi output optimization (MOO) in high speed CNC turning of AISI P-20 tool 
steel," Expert Systems with Applications, vol. 38, no. 6, pp. 6822$6828,2011$.

[23] N. Mandal, B. Doloi, B. Mondal, and R. Das, "Optimization of flank wearusing Zirconia Toughened Alumina (ZTA) cutting tool: taguchi method and regression analysis," Measurement, vol. 44, no. 10, pp. 2149-2155, 2011.

[24] R. K. Roy, "A Primer on the Taguchi Method, Competitive Manufacturing Series," Van Nostrand Reinhold, New York, pp. 780, 1990.

(C) Wenqiang et al.; Licensee Bentham Open.

This is an open access article licensed under the terms of the (https://creativecommons.org/licenses/by/4.0/legalcode ), which permits unrestricted, non-commercial use, distribution and reproduction in any medium, provided the work is properly cited. 